\title{
Elaborating the Correlates of Firearm Injury Severity Combining Criminological and Public Health Concerns
}

\author{
Eric Grommon \\ School of Public and Environmental Affairs \\ Indiana University Purdue University - Indianapolis \\ 801 W. Michigan Street, BS 4067 \\ Indianapolis, Indiana 46202 \\ (O) 317.278.9481 \\ (F) 317.274.7860 \\ egrommon@iupui.edu \\ Jason Rydberg \\ Department of Criminology and Justice Studies \\ University of Massachusetts - Lowell \\ 113 Wilder Street, HSSB $4^{\text {th }}$ Floor \\ Lowell, Massachusetts 01854 \\ (O) 978.934 .4139 \\ (F) 978.934 .3077 \\ jason_rydberg@uml.edu
}

The authors would like to thank Dr. April Brill, D.O., Fellow of the American College of Osteopathic Emergency Physicians (FACOEP), for her critical reviews and commentary on early versions of this article. Additionally, many thanks to Ryan Martz for his assistance in collecting and interpreting regency gaggle data.

This is an Accepted Manuscript of an article published by Taylor \& Francis in Victims \& Offenders on November 21, 2014, available online:

http://dx.doi.org/10.1080/15564886.2014.952472 


\title{
ELABORATING THE CORRELATES OF FIREARM INJURY SEVERITY COMBINING CRIMINOLOGICAL AND PUBLIC HEALTH CONCERNS
}

\begin{abstract}
This research addresses recent calls to incorporate multidisciplinary approaches in the study of firearm violence by utilizing an elaborated criminal events perspective to explore the correlates of firearm injury severity. A unique dataset of non-fatal firearm injury data are derived from official police reports, allowing the use of a medically-validated measure of injury trauma in place of more typical injury indicators. The relative and collaborative contributions of criminological and public health indicators for explaining variation in levels of injury severity are assessed. Multinomial logit models suggest that critical injuries are more likely among older victims, victims who knew their assailants, and victims who refused to cooperate with police. Additionally, the likelihood of critical victim injuries decreased as the time to report an incident to the police increased. The strongest correlates were measures of incident circumstances and the number of gunshot wounds a victim received. In all, these results reveal that a combination of measures from both fields is needed to provide a deeper understanding of injury severity outcomes.
\end{abstract}

Keywords: firearm violence, victimization, injury, Abbreviated Injury Scale

\section{Citation}

Grommon, E., \& Rydberg, J. (2014). Elaborating the correlates of firearm injury severity: Combining criminological and public health concerns. Victims \& Offenders. Online ahead of print. DOI: 10.1080/15564886.2014.952472 


\section{ELABORATING THE CORRELATES OF FIREARM INJURY SEVERITY COMBINING CRIMINOLOGICAL AND PUBIC HEALTH CONCERNS}

The role of firearms in incidences of violence-related injury and trauma has been widely documented (Centers for Disease Control and Prevention [CDC], 2014). Though the lethality of firearms when they are used in injurious attacks is a matter deserving of its own scholarly attention (e.g., Felson \& Messner, 1996), the majority of individuals who sustain a gunshot wound survive the incident. Indeed, in 2012 for every firearm homicide in the US there were nearly 7 shooting victims that survived a criminal incident (US Department of Justice, 2013; CDC, 2014). Previous examinations of national data have consistently shown that of these non-fatal firearm injuries, more than half are the result of interpersonal assaults (Cherry et al., 1998; Coben \& Steiner, 2003; Gotsch, Mercy, \& Ryan, 2001; Zawitz, 1996). These proportions vary across urban and rural landscapes, whereas in urban areas the proportion of firearm injuries being incurred by a criminal assault are often significantly higher than in rural areas (Cummings, LeMier, Keck, 1998; Nance et al., 2002).

Incidences of firearm injuries come at a substantial cost. In a recent report, Howell and Abraham (2013) estimated an annual medical treatment cost of \$630 million for victims of firearm assaults. Nearly 80 percent of these costs will be subsidized by taxpayers. The psychosocial impact of injury creates a lasting toll on individuals and their families that is difficult to quantify (Greenspan \& Kellerman, 2002). Rice and MacKenzie (1989) noted that gunshot victims had to navigate through complex regulations to access long-term rehabilitative care and fulfill immediate needs such as medication, medical equipment, and housing. 
Two fields of inquiry have been used in parallel to develop knowledge on firearm-related injury outcomes for victims of interpersonal violence. Criminological literature has concerned itself with examining the contextual determinants of non-fatal injuries (Tillyer, Miller, \& Tillyer, 2011). In general, much of this work has focused on the likelihood and extent of victim injury among specific criminal acts such as robberies, sexual assaults, and generalized assaults (Tillyer \& Tillyer, 2014). Public health and medical researchers have been primarily concerned with elucidating the role of firearms in the nature and severity of injuries from a primary prevention and medicinal perspective. This literature examines the role and influence of responses to criminal acts that directly contribute to victim injury outcomes (see Crandall, Sharp, Unger, et al., 2013; Papadopoulous, Kanakaris, Danias, et al., 2013).

Both disciplines have made significant contributions to knowledge on the role of firearms in criminal acts with injurious outcomes. An integrative research approach which draws upon and blends criminological and public health perspectives can provide a more complete understanding of firearm injury severity. Indeed, the National Institute of Justice’s Research Working Group on Firearms and Violence (2012) and the Institute of Medicine and National Research Council (2013) recently recommended a similar multidisciplinary focus as a priority for research and data collection on firearm violence. Informed by the criminal events perspective (Meier, Kennedy, \& Sacco, 2001; Sacco \& Kennedy, 1994), the present inquiry explores the interrelationships between criminological and public health factors on the severity of victim injury with unique data on non-fatal events in a large, industrialized Midwestern city. This topic is particularly salient for scholars and practitioners across disciplines who are seeking to promote and 
develop interagency surveillance networks to share data, understand local problems, identify risk and protective factors, and develop preventative firearm violence solutions in urban areas with community partners.

\section{Conceptual Framework}

The criminal events perspective (CEP) is an analytical heuristic used to simultaneously order and analyze offender, victim, location, and contextual information to understand and explain criminal events and their associated outcomes (Meier et al., 2001; Sacco \& Kennedy, 1996). The perspective is not concerned with criminal motivation, but with the occurrence of particular criminal events in particular circumstances (Weaver et al., 2004). Reframing the focus away from instances of individual criminal behavior towards criminal events enables scholars to focus on the situated transactions or sequential history of how such events occur (Luckenbill, 1977; Meier et al., 2001). Criminal events generally unfold through three phases: precursors, transactions, and aftermaths (Meier et al., 2001). Precursors are situational and spatiotemporal factors that bring individuals together in time and space. Transactions are interactions between individuals that have led to an act of crime being committed. This phase defines the criminal act as well as the immediate outcome of the criminal action. Aftermaths are the consequences of the criminal acts and outcomes after the act has occurred for offenders, victims, and the broader community. Importantly, aftermaths also include reactions and responses of law enforcement and other third party agencies directly or indirectly affiliated with the criminal justice system. Meier et al. (2001) 
contend that criminal acts cannot be understood without attention to all phases of an event.

CEP has been previously applied to a variety of events, including lethal or nonlethal outcomes in injurious assaults (Ganpat, van der Leun, \& Nieuwbeerta, 2013; Mieczkowski \& Beauregard, 2010; Weaver et al., 2004), with the emphasis on precursors and/or transactions with the likelihood of a criminal act, likelihood of victim injury, or the extent of victim injury serving as a final outcome. Few studies have explored aftermaths when it comes to the role and reactions of third parties on an outcome of interest. For instance, Ganpat et al. (2013) examine the role of third parties in violent events by operationalizing such parties as guardians, bystanders, or witnesses who were present but exogenous to the victim-offender transaction. Third party presence in this instance is measured prior or in parallel to the criminal act.

Concerning lethal or non-lethal injury outcomes of criminal acts, Weaver et al. (2004) note the importance of third party medical response and intervention after the commission of a crime as aftermath factors. However, Weaver et al. (2004) did not capture information on third parties to determine their influence on criminal events resulting in lethal or non-lethal outcomes. Without more of a focused effort on reactions to criminal acts, administrators, practitioners, and scholars still do not possess adequate knowledge about all facets of criminal events (Meier et al., 2001).

Public health provides a useful framework to further elaborate aftermaths of criminal acts, explore the role of third parties, and provide a deeper understanding of criminal events. For instance, Crandall and colleagues (2013) examined a large sample of victims who incurred gunshot wounds in Chicago from interpersonal assaults. 
Transport time and distance to trauma treatment centers were found to be important factors in determining the likelihood of victim mortality. Victims who experienced longer transport times and were delivered to trauma centers more than five miles away from an event location were more likely to have their gunshot injury turn fatal. Additional research has suggested that the timeliness of medical response is highly correlated with the severity of victim gunshot wound injuries and likelihood of mortality (Feero, Hedges, Simmons, \& Irwin, 1995; Fiedler, Jones, Miller, \& Finley, 1986; Gervin \& Fischer, 1982). Conveyance by ambulance or police units to trauma centers does not appear to influence victim injury severity or mortality (Band, Salhi, Holena, et al., 2014), but victims who are transported by private, non-emergency means tend to have better survival outcomes relative to victims who delivered to trauma centers by emergency services (Demetriades et al., 1996).

Consistent with CEP, public health and medical researchers have made significant contributions about the relationship between response processes that occur after a criminal act and victim injury outcomes. Unification of criminological knowledge on precursors and transactions with public health research on aftermaths extends the temporal ordering of the CEP framework. Through this integrative elaboration of the criminal events perspective new insights on injurious victim outcomes can be developed.

\section{Literature Review}

Determinations of victim injury severity have been limited by an assortment of measurement challenges. Nearly three decades ago, Allen (1986: 141) reviewed attempts of criminologists to measure injury severity, and noted that the most prominently used 
measures at that time "have been neither medically accurate injury descriptions nor medically acceptable assessments in injury severity.” These measures include discrete forms of trauma or hospitalizations. In their place, Allen advocated the use of medical trauma-scoring scales. Despite the fact that more recent scholarship has also advocated the use of such scales in criminological analysis (Harris, Thomas, Fisher, \& Hirsch, 2002; Safarik \& Jarvis, 2005), the majority of studies in this area continue to use injury indicators that Allen (1986) had criticized.

Previous criminological examinations have tended to measure the extent of victim injury as dichotomies differentiating any injury from no injury, or minor injuries from severe injuries. For instance, those inquiries utilizing the National Crime Victimization Survey (NCVS) by necessity follow the injury definitions utilized by the instrument. Injury information is captured by asking about injuries sustained, with possible responses including ‘None’, ‘Knife or stab wounds’, ‘Gunshot, bullet wounds’, ‘Broken bones or teeth knocked out', or 'Knocked unconscious’ (Bureau of Justice Statistics, 2012). A common approach in the literature is to use the presence of particular categories to represent serious injuries (e.g., Tark \& Kleck, 2004). An alternative means to capture injury severity in the NCVS is whether the victim received medical care, with treated injuries assumed to be serious (e.g., Apel, Dugan, \& Powers, 2013; Cook, 1987; Hindelang, Gottfredson, \& Garafalo, 1978; Schnelby, 2002). Because of the nature of data collection, injury information is captured through victim self-report and recollection of the past six months. As such, the measure of injury severity is unable to capture information on immediate injuries and also requires recall and adequate description of injury by a victim. 
More recent inquiries have utilized the National Incident Based Reporting System (NIBRS) to measure victim injury. Like the NCVS, the NIBRS captures victim injury severity through non-mutually exclusive discrete trauma categories. For a NIBRS reported incident, victim injury values include 'None’, 'Apparent broken bones', 'Possible internal injury’, ‘Severe laceration', ‘Apparent minor injury’, and 'Unconsciousness' (U.S. Department of Justice, 2013). This information is gleaned from administrative incident reports. The extent of victim injury is captured at the time of the report by responding law enforcement personnel who must identify injuries or seek information from victims or collateral contacts to report injuries. Research utilizing the NIBRS has used the presence of particular categories to indicate serious injuries (e.g., Tillyer et al., 2011; Tillyer \& Tillyer, 2014). Inquiries which have not utilized these forms of data collection deploy similar injury indicators. For instance, several studies use hospitalization to indicate injury severity (Wells \& Horney, 2002; Zimring \& Zuehl, 1986).

These common approaches to measuring victim injury severity in criminology have provided a number of insights, but also have suffered from several challenges. For instance, the use of hospitalization as an injury indicator conflates measures of medical treatment with physical trauma. Allen (1986) points out that hospitalization may occur to stabilize or to observe minor injuries, which would render it suspect as a measure of injury severity. Similarly, identical injuries may differ in the likelihood of hospitalization if one was reported more quickly than the other. In such a case, the hospitalization would be due to the speed of reporting, rather than trauma severity (Allen, 1986). Utilizing discrete categories of trauma also introduces measurement error to indicators of injury 
severity. Although customary for analyses of NCVS data, automatically categorizing stabbings and gunshot wounds as "severe" injuries assumes an immediate connection between weapon type and severity, regardless of the physiological trauma suffered by the victim. Additionally, Allen (1986) warns against combining discrete trauma and hospitalization into severity indicators (e.g., Melde \& Rennison, 2008), because it introduces unmeasured multidimensionality into the severity variable.

A variety of medical scoring scales have been designed and used by trauma centers over the past 50 years to standardize injury severity classifications (Osler, Nelson, \& Bedrick, 1999). Available scales have largely been developed by professional medical organizations or committees of physicians who rely primarily on members' experience and judgment in assessing the likelihood of fatality of an injury or injuries to a body region (Baker, O’Neill, Haddon, \& Long, 1974; MacKenzie, Shapiro, \& Eastham, 1985). Given the institutionalized use of scoring scales and direct assessment of injury by a medical professional to determine severity, such measures hold great value for multidisciplinary research on injurious outcomes from firearm violence.

\section{Correlates of Victim Injury}

The use of firearms has been observed to have mixed effects on differentiating the risk of injury from injury severity. Several studies have observed that the presence of a gun in a victimization incident tends to lower the probability of injury. This finding was first observed by Hindelang, Gottfredson, and Garafalo (1978), and replicated within particular crime types, including robberies (Cook, 1987; Tillyer et al. 2011), in potentially violent situations (Kleck \& McElrath, 1991; Wells \& Horney, 2002), in 
assaults (Baumer, Horney, Felson, \& Lauritsen, 2003; Tillyer et al., 2011; cf. Nielsen, Martinez, \& Rosenfeld, 2005; Tark \& Kleck, 2004), and in gang perpetrated violence (Melde \& Rennison, 2008). Victimizations involving the presence of a firearm may be at a lower likelihood of injury considering accuracy issues in firearm use (Kleck \& McElrath, 1991). On the other hand, previous inquiries (Cook, 1987; Melde \& Rennison, 2008; Schnelby, 2002; Wells \& Horney, 2002; Zimring \& Zuehl, 1986) have observed that while the presence of a gun in robberies and assaults was negatively related to the likelihood that a victim incurred an injury, the likelihood of hospitalization was increased. An interpretation of this finding is that the presence of a gun reduces the likelihood of injury, but when an injury does occur it is more likely to be a serious one.

This literature has also produced findings concerning the situational and environmental context of victim injury. The risk of an injury occurring in a victimization has been positively related to the victim being male (Tillyer et al., 2011; Tillyer \& Tillyer, 2014; cf. Melde \& Rennison, 2008), the victim being older (Tillyer \& Tillyer, 2014), and the number of offenders (Melde \& Rennison, 2008). The role of victimoffender relationship has been inconsistent, as offenders being known to the victim has both increased (Hindelang et al., 1978; Tillyer \& Tillyer, 2014) and decreased the risk of injury (Melde \& Rennison, 2008; Nielsen et al., 2005). Concerning the correlates of injury severity, these studies observed that severe injuries were more likely if the attacker was a stranger to the victim (Felson \& Messner, 1996; cf. Cook, 1987), if the victim was a black male (Schnelby, 2002; Zimring \& Zuehl, 1986), or took place on the street, as opposed to a residence (Zimring \& Zuehl, 1986; cf. Tark \& Kleck, 2004). The theoretical rationale for spatial and temporal variation in injury severity comes from a 
routine activities perspective, positing that particular locations and times (e.g., secluded, dark) allow for a higher “quality” of violence (Baumer et al., 2003; Tillyer \& Tillyer, 2014).

\section{The Current Inquiry}

Informed by an elaborated criminal events perspective, this research seeks to add to the literature on victim injury severity through the examination of two related sets of hypotheses. First, this study explores the relationship between criminological and public health factors on the extent of victim injury from criminal acts involving the discharge of a firearm. It is anticipated that common precursor and transaction factors derived from criminological literature about the event and its spatiotemporal context will differentiate levels of victim injury severity. Equally important are aftermath factors associated with medical responses to a traumatic injury. These public health factors should adequately distinguish levels of injury severity. Finally, a combination of precursor, transaction, and aftermath measures across criminological and public health fields are expected to demarcate the extent of victim injury better than either variable set in isolation.

Second, this study examines the relationships between criminological and public health indicators on victim injury severity when severity is measured with a medical scoring scale. This enables a partial test of the robustness of existing correlates of victim injury severity. According to Allen’s (1986) critique, common criminological correlates of victim injury severity may have mixed effects when a measure of injury severity derived from medical assessment is used. 


\section{Data and Methods}

Non-fatal shooting data from a large, industrialized, Midwestern city were used for the present study. These data were collected as part of a broader multiagency evaluation of a strategic firearm intervention. Across a two year post-intervention period partnerships were formed to exchange and document relevant victim injury data from citywide non-fatal shooting events in official police reports. To be included in the dataset, a shooting in which a victim sustains a gunshot wound occurs and is reported to the police. The surviving victim is conveyed to a trauma center in which they are examined by medical personnel and their injury is scored via a trauma scale. This scale value was communicated to the reporting officer, who filed the information in an incident report. All of the victims included in the dataset survived during this period of observation. Fatalities, including victims who were dead on scene or dead on arrival, were not made available or included in the data.

The data used for the current study were gleaned from these reports. The median lapse between a non-fatal shooting and the first filed report was 15 minutes $(M=45, S D$ $=105.80$ ). As such, these data overcome some of the inherent challenges of unknown elapsed times between incident occurrence, report documentation, and medical response found in NCVS and NIBRS data collections. Although the speed of the reports negatively affected the availability of data which would have been expected given a completed investigation (e.g., offender characteristics), these data capture relevant and timely information on situational and contextual factors associated with an incident as well as summary response information from local trauma centers. This information typically is not captured in publicly available summary or incident-based data systems, 
giving these data unique insight into event circumstances and victim injury severity immediately following a non-fatal shooting.

The final dataset consisted of 1,417 non-fatal victims of interpersonal firearm violence. Multiple victims of a single criminal event were included as separate observations since the emphasis of this research is on injurious outcomes at the individual level of analysis. The maximum number of multiple non-fatal victims from a single criminal event was two. ${ }^{\mathrm{i}}$ Victims from incidents deemed to be accidental discharges or suicide attempts and those involving the police were removed from analysis. The final sample represents consecutive non-fatal shooting events that occurred in the city and consecutive victims throughout the two year period of observation.

\section{Dependent Variable}

Victim injury severity is an ordinal variable that measures the extent of injury sustained by a non-fatal shooting victim. Injury severity is measured by the Abbreviated Injury Scale (Civil \& Schwab, 1988; Copes, Lawnick, Champion, \& Sacco, 1988). The instrument is the most widely used scale among medical professionals to classify, summarize, and standardize the severity of incurred injury (Stevenson, Segui-Gomez, Lescohier, Scala, \& McDonald-Smith, 2001). Damages to anatomical structures and body regions are clinically assessed with emphasis on dimensions of survivability, likelihood of permanent impairment, length of subsequent medical treatment, and the amount of external energy dissipated within one’s body (MacKenzie et al., 1985; Salottolo, Settell, Uribe, et al., 2009). Based upon these criterions, an injury severity score is assigned ranging in value from one (minor) to six (maximal). 
Injury severity scores in this study were estimated by medical personnel of local trauma centers who were trained and had experience administering the Abbreviated Injury Scale (AIS). This scale is universally utilized in all emergency departments in the study city. All of the injury severity assessments were made after trauma center admission once medical interventions had begun to be delivered. Injury severity determinations were subsequently shared with the responding police officer for inclusion in official reports as soon as the assessment was complete. Only the AIS for the most serious wound was reported in the available data.

Given a sample which consisted of victims who incurred a gunshot wound, severity scores were observed to cluster around three values: moderate, serious, and critical. These three values of increasing injury severity serve as the dependent variable. Moderate and serious represent non-life threatening injuries, with serious classifications representing more severe injuries and higher probability of death than moderate classifications. Critical classifications reflect life threatening injuries where survival is highly uncertain. For the entire sample, $44 \%$ of victims were assessed with a moderate injury, $44 \%$ serious, and $12 \%$ critical.

\section{Independent Variables}

Independent variable groupings were used to explore variations in victim injury severity. Blocks of variables from criminological literature draw upon knowledge developed on incident and spatiotemporal characteristics. Often, these characteristics are associated with precursors and transactions according to the criminal events perspective. 
Medical response characteristics are informed by public health inquiries into firearm injuries and represent aftermaths of the criminal events perspective.

Individual and Incident Characteristics. Victim age is the age of the victim in years. Male victim is a dummy variable to compare male victims against the reference category of female victims. Non-black victim is a dummy variable that compares nonblack victims against the reference category of black victims. Number of offenders captures information on the number of offenders present. Known victim-offender relationship is a dummy variable indicating instances in which the victim had some degree of relations with the offender, with the reference category being those cases where the victim and offender were either unacquainted or victims and witnesses were unable to determine whether they knew the offender.

Four additional dummy variables are used for classification of incident circumstances. Incidents were coded as being attempted or completed robberies (robbery), stray bullets and random crossfires (random), or refusal of information at the time of the report (refused information). Aggravated assault (assault) serves as the reference category. The classification of incidents was informed by discussions with police administrators, who confirmed the generalized classification categories. From these discussions, it was determined that a distinct classification of "refused information" was needed to accurately capture and measure incident circumstances. This classification consists of reports where victims were unwilling to discuss or reveal further information about the incident to the responding officer beyond basic reporting information.

Spatiotemporal Characteristics. Several variables were used to describe the location and timing of the shooting incidents. Four dummy variables were used to 
categorize incident locations. Private locations are incidents that occur within a private residence, home, or apartment. Business locations are incidents that occur within a place of business. This measure includes businesses such as convenience stores, gas stations, car repair centers, taverns and bars, and other places of retail. Semi-private refers to locations adjacent to or in the immediate vicinity of private residences and businesses. This measure attempts to parcel out spillover incidents that occur outside and in the immediate vicinity of private and semi-private property. The reference category refers to public locations (public). These locations occur in public areas such as parks, fields, streets, alleys, sidewalks, and open air parking lots. Night time is a dummy variable capturing incidents that occurred between 8:00 p.m. and 4:00 a.m. Weekend refers to incidents that occurred on Friday, Saturday, or Sunday.

Medical Response Characteristics. Multiple Gunshot Wounds (GSW) is a binary indicator of whether the victim incurred more than one gunshot wound. This measure was captured at the scene by the responding officer and corroborated by medical personnel. Time to report captures the time lag between the incident and the first report to the police in minutes. It is a proxy of how much time elapsed before medical treatment could have been delivered. Primary trauma refers to whether the victim was treated at the primary trauma treatment center in the city, which processes the highest frequency and proportion of gunshot wound victims. It is anticipated that the most serious cases will be brought to this location, and thus should be associated with some observed variation in the dependent variable. The reference category refers to the remaining three trauma centers in the city. Ambulance convey indicates instances in which the victim was transported to a treatment center by ambulance and is contrasted against the reference 
category of private conveyance where a victim drove or walked himself or herself to treatment. It is anticipated that ambulance conveyance may provide care to the injury prior to scoring at the hospital, and thus may be associated with some variation in injury severity. Distance to treatment measures the Euclidian distance in miles between the incident address and the treatment center address in miles. This measure was calculated using address and cross-street points in ArcGIS.

\section{Missing Data}

One of the challenges facing research on victimization and injury is missing data, especially among official data sources. Due to their production immediately following a shooting incident this is a necessary trade-off with non-fatal data used for this study. Multiple imputation using chained equations (MICE) was used to retain cases for analysis. MICE is a multiple imputation technique which uses a series of regression models to generate imputations for each variable with missing values (White, Royston, \& Wood, 2011). Compared to standard multiple imputation, MICE does not assume that all variables with missing data follow a multivariate normal distribution. Separate imputation models are specified for each variable in the dataset, giving MICE the ability to flexibility impute values for continuous, binary, ordinal, and categorical variables (Lee \& Carlin, 2010). To generate imputed datasets, each variable is treated as an outcome and regressed on all other variables in the imputation model. This procedure is repeated to create a number of datasets with imputed values $(m)$, where analyses are run on each dataset separately and the results are pooled to create single estimates for regression coefficients and standard errors (Johnson \& Young, 2011). Given the extent of missing 
data in the current dataset 50 imputations were performed in Stata using the "mi impute chained" function.

Table 1 provides information on the independent variables that were imputed using the MICE procedure. The most problematic were measures of offender demographics. This is primarily due to the nature of the non-fatal shooting data;

offender(s) typically had not been identified when the data were generated. While the imputation of offender demographics can be completed (see Fox \& Swatt, 2009; Gruenewald \& Pridemore, 2012), the current data has substantially more missing offender information than these previous studies. When there is a large amount of missing data the Monte Carlo error of imputed estimates becomes unacceptably large (White et al., 2011). Bivariate analyses of offender demographics using known data indicate no significant relationships between offender age $\left[\chi^{2}(2,476)=2.09, p=.35\right]$, gender $\left[\chi_{(2,787)}^{2}=5.55, \mathrm{p}=.06\right]$, or race $\left[\chi^{2}(2,756)=.57, \mathrm{p}=.75\right]$ on victim injury severity. The nearly significant estimate for offender gender was driven largely by the small number of known female offenders $(\mathrm{N}=27)$. Since these measures are unable to differentiate levels of injury severity, the decision to drop offender demographic measures from multivariate analyses was made.

\section{[INSERT TABLE 1 ABOUT HERE]}

\section{Analytic Strategy}

Given the exploratory nature of this research, bivariate analyses are first conducted on pre-imputed, known data to ascertain if there were any unconditional relationships between independent variables and victim injury severity. Listwise deletion of unknown or missing cases provides some information on bivariate relationships. 
These estimates must be interpreted with caution as listwise deletion can artificially inflate or deflate standard errors and bias estimates (Little \& Rubin, 2002). Chi-square and ANOVA mean difference tests are used to examine unconditional relationships. Bonferroni adjustments are made to ANOVA estimates.

Imputed data are used for multivariate analyses. Independent variable groupings for criminological and public health variables are entered as separate blocks to multinomial logistic regression models. The first model iteration tests the effects of criminological variables irrespective of public health variables. In essence, this model assesses the relationship between precursor and transaction measures on victim injury severity. The second model iteration tests the effects of public health or aftermath variables on victim injury severity. A fully conditional third iteration model includes both sets of variables.

Although the dependent variable is measured at the ordinal level, multinomial logistic regression is used due to likelihood ratio and Brant test diagnostics detecting violations of the proportional odds assumption of the ordinal logistic regression model (Brant, 1990; Long, 1997). This procedure allows for observations of the relative and moderating influence of specific factors with conditional models. A number of independent variables were transformed into standardized z-scores. These include victim age, number of offenders, time to report, and distance to treatment. Victim injuries designated as critical served as the reference category for the dependent variable.

\section{Results}


The bivariate results offer support for both criminological and public health variables as correlates of victim injury severity (see Table 2). Victims who incurred a critical injury were approximately two years older than other victims. Victims who knew their offender were more likely to be seriously injured, whereas victims who did not know their offender tended to be moderately injured. Robberies and random gunfire tended to result in moderate or serious injuries. Assaults often resulted in serious injury outcomes. Incidents in private locations were related to serious injury outcomes while semi-private locations were associated with moderate injuries. Incidents that occurred within businesses or on the street tended to result in moderate or serious injuries.

Among public health variables, victims who received multiple gunshot wounds had more severe injuries. Time to report was negatively associated with victim injury severity. On average, critical injuries were reported at least 18 minutes faster than other injuries. Victims transported by ambulance were slightly more likely to have received serious or critical injuries than those who arrived to a trauma center by other means.

\section{[INSERT TABLE 2 ABOUT HERE]}

Table 3 displays a summary of the multinomial logistic regression results, with estimates representing averages across the 50 imputed datasets. Model 1 estimates the conditional effects of criminological variables. Incident characteristics were associated with victim injury severity while spatiotemporal characteristics were unrelated to injury outcomes. Older victims were more likely to have incurred critical injuries. Events where the police were refused information about the circumstances were also more likely to result in critical injuries relative to assaults. These events were associated with the most severe injury outcomes when compared to the non-significant directional effects of 
the remaining circumstances. Victim-offender relationship only differentiated moderate injuries from critical injuries, whereas victims who knew their offender were more likely to have incurred critical injuries.

Model 2 examines the relative effect of public health variables irrespective of criminological variables. Victims who were transported to a treatment center via emergency ambulance were significantly more likely to have received a critical injury as opposed to a less severe, moderate injury. However, the effect of conveyance was unable to distinguish serious from critical injury classifications. Among the strongest correlates of victim injury severity in Model 2 is the number of gunshot wounds victims received. Multiple gunshot wounds were more likely to result in critical injuries relative to victims who suffered from a single gunshot wound. None of the remaining response characteristics were associated with injury outcomes.

Model 3 estimates a full conditional model including criminological and public health variables. Relative to Models 1 and 2, delta Akaike and Bayeseian information criteria calculations suggest that Model 3 provides the best fit. The entry of public health variables into the multinomial logistic regression equation moderates the relationship between victim age and victim injury severity when differentiating injury severity outcomes at their extremes. Additionally, the mode of conveyance to a treatment center no longer distinguishes moderate injury from critical injury outcomes once criminological variables are considered. Criminological variables amplify the effect of the time to report. Holding all other variables constant, a one standard deviation increase in the elapsed time to report increases the odds of a serious injury by $38 \%$ relative to the 
baseline risk of critical injury amongst the victims and implies that faster response times are more likely affiliated with critical injuries.

Beyond these observations, the fully conditional model results are largely consistent with the estimated effects of Model 1 and Model 2. To provide further elaboration of the multivariate results, predicted probabilities were calculated using inverse-logit transformations of estimated coefficients. These probabilities were specified to reflect the reference category, which allows for the interpretation of the probability for a victim's critical injury outcome. Holding all other variables constant at their respective means, the first equation of the full conditional model, comparing moderate versus critical injury outcomes produces a predicted probability of $23 \%$ for critical injury while the second equation (which compares serious versus critical injury) estimates a $21 \%$ probability. As such, the baseline predicted probability of critical injury is $21 \%$ to $23 \%$.

The strongest effects on injury severity derived from the number of gunshot wounds victims received. Predicted probabilities of critical injuries increased 29\% to $35 \%$ for victims who received multiple gunshot wounds relative to those who received a single wound. Events where information about the circumstances were refused were more likely to result in critical injuries when compared to assaults. These instances increased the predicted probability of critical injury in both equations by $19 \%$ to $21 \%$ relative to the baseline model. Victims who knew their offender were more likely to receive serious or critical injuries rather than moderate injuries. The predicted probability of a critical injury outcome increased from $23 \%$ to $44 \%$ for victims who knew their offenders. Amongst the oldest victims in the sample (i.e., more than two standard 
deviations from the mean), the predicted probability of a critical injury outcome increased from $21 \%$ to $33 \%$.

\section{[INSERT TABLE 3 ABOUT HERE]}

\section{Sensitivity Checks}

Several steps were taken to check the sensitivity of the analyses to the imputation procedure. Multiple imputation with chained equations can produce slightly different results with each analysis across $m$ datasets. Across all of the models, the average relative variance increase was .10 or less. Estimated coefficients possess a slightly inflated variance due to missing observations and imputations, but the rate of inflation observed was not problematic (White et al., 2011). The estimated largest fraction of missing information (see Table 3; FMI statistics) indicates that the imputation procedure is sufficient for analysis. Convergence of the imputation models was also checked through a subanalysis of descriptive statistics across model iterations. No discernable pattern was observed in the between iteration variation. Additionally, assessments of acceptable, random Monte Carlo error were made through the examination of each imputed dataset following the guidelines established by White et al. (2011). Including the two variables with the highest degrees of missing data (number of offenders and ambulance convey), none of the predictors used in the multinomial logistic models indicated problems with inflated random errors that would bias estimates.

\section{Discussion}

This research used an elaborated criminal events perspective to examine the severity of nonfatal injury outcomes among victims of firearm violence. Central to this 
research was an exploration into how the individual and joint contributions of criminological and public health fields would differentiate the severity of injury outcomes resulting from non-fatal shootings. The robustness of these factors was examined through the integration and use of a medical trauma scoring scale, which increases the specificity and validity of injury severity measurement and heeds relatively unanswered calls from Allen (1986).

The results provide a number of valuable insights. Despite a loss of parsimony, the best model fit was produced with the inclusion of precursor, transaction, and aftermath indicators. Specific information on the medical response, such as the number of wounds received from a criminal act, is a central correlate of injury severity outcomes. Inclusion of medical response measures can also extend the knowledge base on the correlates of injury severity. These measures moderated relationships between victim age and injury severity, which have been previously offered as important correlates of injury outcomes from criminological and public health fields.

An emphasis on medical response measures must be balanced with some attention to incident characteristics used in criminological literature. Results from this study confirm the importance of victim-offender relationships and incident circumstances. Victims who knew their offenders were consistently more likely to have incurred a critical injury rather than the least severe injury classification. Extrapolating from the overall results, there appears to be more latent intent to injure between individuals who have some previous knowledge of one another. This is consistent with relational distance perspectives, which holds that closer relationships can increase injury severity while strangers are less likely to inflict serious injury (Apel et al., 2013; Boyle \& Hassett- 
Walker, 2008). Social network analysis has also indicated that the risk of gunshot injury is related to one's immediate or peripheral associates (Papachristos, Braga, \& Hureau, 2012).

Incidents where the police were refused information about the circumstances at the time of report were more likely to result in critical injuries across all models when compared to assaults. It is difficult to disentangle the meaning behind this result. While these circumstances are not entirely clear, police administrators suggested these incidents are qualitatively different from the assault or robbery classifications. Such incidents are viewed by administrators as being reflective of proverbial street codes of maintaining distance and communication with law enforcement (see Anderson, 1999; Goffman, 2009). Viewed with this lens, these incidents may be products of retaliation for past incidents or are triggers for future retaliations (Jacobs \& Wright, 2006). Unfortunately longitudinal data on the sample is not available to elucidate this association.

It is important to learn from the null findings generated from this research. Two results are particularly salient. First, spatiotemporal circumstances had no effect on injury severity, which is contrary to some recent research (Tillyer et al., 2011; Tillyer \& Tillyer, 2014). Such circumstances may only be associated with particular outcome measures of injury gleaned from NCVS or NIBRS but are not robust enough to differentiate outcomes amongst victims whose injury was assessed with a medical scoring scale. Second, this research finds important components of responding to a nonfatal shooting victim are only related injurious outcomes when they are considered independently or in combination with other relevant correlates of injury. The timing of response was not associated with injury severity considering only response 
characteristics, but was able to differentiate serious injuries from critical injuries in the full conditional model. The direction of the effect suggests that more serious injuries are reported more quickly, while more time is allowed to elapse for less serious injuries. Method of conveyance served as an important correlate for response characteristic models seeking to differentiate moderate injuries from serious injuries but was no longer associated with victim injury severity in the full model. Technological improvements in medical responses are used as explanations for non-fatal victim injury outcomes (see Giacopassi, Sparger, \& Stein, 1992; Harris, Thomas, Fisher, \& Hirsch, 2002), but measures of medical response characteristics used in this research were mixed and largely unrelated to victim injury severity.

A few important limitations must be considered. First, strength of these data generated immediately after an incident - is also a weakness. Imputation was necessary to maximize the amount of observations used for multivariate models. One of the main controversies with imputation used here is the assumption that missing values are missing at random (MAR). The imputation model used included all of the predictors in an attempt to minimize violations of the MAR assumption (White et al., 2011). Additionally, while this assumption cannot be tested directly (Schaefer \& Olsen, 1998), correlations between variable missingness revealed no relationships strong enough to suggest that MAR had been violated. Second, the findings may have limited generalizability. These data were obtained from official reports from one large-sized police department in an industrialized, Midwestern city. As this police department responds to a high number of both fatal and non-fatal shooting victims each year, the capacity of first responders and trauma centers to deliver treatment may be unique to the 
study city. Finally, the abbreviated injury scale is not immune to criticism. The reliability of the measure has been questioned as scale score determinations may be influenced by the training of medical personnel (MacKenzie et al., 1985; Osler et al., 1999; Salottolo et al., 2009). Medical response and trauma characteristics were used in multivariate models to control for this variation.

Cautionary implications can be deduced from this research to inform future research and policy. The results suggest that a combination of criminological and public health measures is needed to explore the correlates of injury severity. Information on victim-offender relationships, circumstances of the incident, and preliminary information on the inflicted injury at the scene are essential. At the same time, these results generally confirm Allen’s (1986) conceptual concerns. The extant body of knowledge on injurious outcomes which rest predominantly on measures of injury or injury severity with questionable validity is far from stable. Much more research is needed to elaborate these exploratory findings and the ramifications of omitted variables.

A fundamental challenge with integrating criminological and public health measures is the ability to capture and include measures from different fields of inquiry. To overcome this hurdle, partnerships must be formed between local police departments and medical or trauma centers to promote and develop surveillance networks to share data. This is no easy task; the ability of local, state, and federal agencies to invest tangible resources to foster partnerships remains an open question (see Institute of Medicine and National Research Council, 2013). With renewed efforts to establish funding streams to launch research initiatives on firearm violence (see National Institute 
of Justice, 2012), this study highlights the potential of shared data and their ability to provide an enhanced understanding of victim injury in criminal incidents.

\section{REFERENCES}

Allen, R. B. (1986). Measuring the severity of physical injury among assault and homicide victims. Journal of Quantitative Criminology, 2(2), 139-156.

Anderson, E. (1999). Code of the streets. New York, NY: Norton and Company.

Apel, R., Dugan, L., \& Powers, R. (2013). Gender and injury risk in incidents of assaultive violence. Justice Quarterly, 30(4), 561-593.

Baker, S. P., O'Neill, B., Haddon Jr, W., \& Long, W. B. (1974). The injury severity score: a method for describing patients with multiple injuries and evaluating emergency care. Journal of Trauma-Injury, Infection, and Critical Care, 14(3), 187-196.

Band, R. A., Salhi, R. A., Holena, D. N., Powell, E., Branas, C. C., \& Carr, B. G. (2014). Severity-adjusted mortality in trauma patients transported by police. Annals of Emergency Medicine, 63(5), 608-614.

Baumer, E., Horney, J., Felson, R., \& Lauritsen, J. (2003). Neighborhood disadvantage and the nature of violence. Criminology, 41(1), 39-72.

Boyle, D. J., \& Hassett-Walker, C. (2008). Individual-level and socio-structural characteristics of violence: An emergency department study. Journal of Interpersonal Violence, 23(8), 1011-1026.

Brant, R. (1990). Assessing proportionality in the proportional odds model for ordinal logistic regression. Biometrics, 46, 1171-1178.

Bureau of Justice Statistics (2012). National Crime Victimization Survey: Crime Incident Report. Available at http://www.bjs.gov/content/pub/pdf/ncvs2_2012.pdf.

Centers for Disease Control and Prevention [CDC]. (2014). Web-based Injury Statistics Query and Reporting System (WISQARS). National Center for Injury Prevention and Control, Centers for Disease Control and Prevention. Accessed May 30th, 2014 from: www.cdc.gov/ncipc/wisqars.

Cherry, D., Annest, J. L., Mercy, J. A., Kresnow, M., \& Pollock, D. A. (1998). Trends in fatal and nonfatal firearm-related injury rates in the United States, 1985-1995. Annals of Emergency Medicine, 32(1), 51-59. 
Civil, I. D., \& Schwab, C. W. (1988). The abbreviated injury scale, 1985 revision; a condensed chart for clinical use. Journal of Trauma, 28, 87-90.

Coben, J. H., \& Steiner, C. A. (2003). Hospitalizations for firearm-related injuries in the United States. American Journal of Preventive Medicine, 24(1), 1-8.

Cook, P. J. (1987). Robbery violence. The Journal of Criminal Law and Criminology, 78(2), 357-376.

Copes, W. S., Lawnick, M., Champion, H. R., \& Sacco, W. J. (1988). A comparison of abbreviated injury scale 1980 and 1985 versions. Journal of Trauma, 28, 78-86.

Crandall, M., Sharp, D., Unger, E., Straus, D., Brasel, K., Hsia, R., \& Esposito, T. (2013). Trauma deserts: Distance from a trauma center, transport times, and mortality from gunshot wounds in Chicago. American Journal of Public Health, 103(6), 1103-1109.

Cummings, P., LeMier, M., \& Keck, D. B. (1998). Trends in firearm related injuries in Washington State, 1989-1995. Annals of Emergency Medicine, 32(1), 37-43.

Demetriades, D., Chan, L., Cornwell, E., Belzberg, H., Berne, T. V., Asensio, J., Chan, D., Eckstein, M., \& Alo, K. (1996). Paramedic v. private transportation of trauma patients: Effect on outcome. Archives of Surgery, 131(2), 133-138.

Feero, S., Hedges, J. R., Simmons, E., \& Irwin, L. (1995). Does out-of-hospital EMS time affect trauma survival? American Journal of Emergency Medicine, 13(2), 133-135.

Felson, R. B., \& Messner, S. F. (1996). To kill or not to kill? Lethal outcomes in injurious attacks. Criminology, 34(4), 519-545.

Fiedler, M. D., Jones, L. M., Miller, S. F., \& Finley, R. K. (1986). A correlation of response time and results of abdominal gunshot wounds. Archives of Surgery, 121(8), 902-904.

Fox, J. A., \& Swatt, M. L. (2009). Multiple imputation of the Supplementary Homicide Reports, 1976-2005. Journal of Quantitative Criminology, 25(1), 51-77.

Ganpat, S. M., van der Leun, J., \& Nieuwbeerta, P. (2013). The influence of event characteristics and actors' behavior on the outcome of violent events: Comparing lethal with non-lethal outcomes. British Journal of Criminology, 53(4), 685-704.

Gervin, A. S., \& Fischer, R. P. (1982). The importance of prompt transport of salvage of patients with penetrating heart wounds. Journal of Trauma, Injury, Infection, and Critical Care, 22(6), 443-448. 
Giacopassi, D. J., Sparger, J. R., \& Stein, P. M. (1992). The effects of emergency medical care on the homicide rate: Some additional evidence. Journal of Criminal Justice, 20(3), 249-259.

Goffman, A. (2009). On the run: Wanted men in a Philadelphia ghetto. American Sociological Review, 74(3), 339-357.

Gotsch, K. E., Annest, J. L., Mercy, J. A., \& Ryan, G. W. (2001). Surveillance for fatal and non-fatal firearm-related injuries - 1993-1998. Washington, D.C.: National Center for Injury Prevention and Control, Center for Disease Control.

Greenspan, A. I., \& Kellerman, A. L. (2002). Physical and psychological outcomes 8 months after serious gunshot injury. Journal of Trauma Injury, Infection, and Care, 53(4), 709-716

Gruenewald, J., \& Pridemore, W. A. (2012). A comparison of ideologically-motivated homicides from the New Extremist Crime Database and homicides from the Supplementary Homicide Reports using multiple imputation with chained equations to handle missing values. Journal of Quantitative Criminology, 28(1), $141-162$.

Harris, A. R., Thomas, S. H., Fisher, G. A., \& Hirsch, D. J. (2002). Murder and medicine: The lethality of criminal assault 1960-1999. Homicide Studies, 6(2), 128-166.

Institute of Medicine and National Research Council. (2013). Priorities for research to reduce the threat of firearm-related violence. Washington, DC: The National Academies Press.

Hindelang, M. J., Gottfredson, M. R., \& Garafalo, J. (1978). Victims of personal crime: An empirical foundation for a theory of personal victimization. Cambridge, MA: Ballinger Publishing.

Howell, E. M., \& Abraham, P. (2013). The hospital costs of firearm assaults. Washington, D.C.: The Urban Institute.

Institute of Medicine and National Research Council. (2013). Priorities for research to reduce the threat of firearm-related violence. Washington, DC: The National Academies Press.

Jacobs, B. A., \& Wright, R. (2006). Street justice: Retaliation in the criminal underworld. New York, NY: Cambridge University Press.

Johnson, D. R., \& Young, R. (2011). Toward best practices in analyzing datasets with missing data: Comparisons and recommendations. Journal of Marriage and Family, 73(5), 926-945. 
Kleck, G., \& McElrath, K. (1991). The effects of weapony on human violence. Social Forces, 69(3), 669-692.

Lee, K. J., \& Carlin, J. B. (2010). Multiple imputation for missing data: Fully conditional specification versus multivariate normal imputation. American Journal of Epidemiology, 171(5), 624-632.

Little, R. J. A. \& Rubin, D. B. (2002). Statistical analysis with missing data (2 ${ }^{\text {nd }}$ ed.). New York, NY: John Wiley.

Long, J. S. (1997). Regression models of categorical and limited dependent variables. Thousand Oaks, CA: Sage.

Luckenbill, D. F. (1977). Criminal homicide as a situated transaction. Social Problems, 25(2), 176-186.

MacKenzie, E. J., Shapiro, S., \& Eastham, J. N. (1985). The abbreviated injury scale and injury severity score: Levels of inter- and intrarater reliability. Medical Care, 23(6), 823-835.

Meier, R. F., Kennedy, L. W., \& Sacco, V. F. (2001). The process and structure of crime: Criminal events and crime analysis. New Brunswick, NJ: Transaction Publishers.

Melde, C., \& Rennison, C. M. (2008). The effect of gang perpetrated crime on the likelihood of non-lethal victim injury. American Journal of Criminal Justice, 33(2), 234-251.

Mieczkowski, T., \& Beauregard, E. (2010). Lethal outcome in sexual assault events: A conjunctive analysis. Justice Quarterly, 27(3), 332-361.

Nance, M. L., Denysenko, L., Durbin, D. R., Branas, C. C., Stafford, P. W., \& Schwab, C. W. (2002). The rural-urban continuum: Variability in statewide serious firearm injuries in children and adolescents. Archives of Pediatrics \& Adolescent Medicine, 156, 781-785.

National Institute of Justice. (2012). Firearms and violence topical working group meeting summary 2011. Accessed May 30 ${ }^{\text {th }}$, 2014 from http://www.nij.gov/topics/crime/gun-violence/working-group/pages/2011summary.aspx

Nielsen, A. L., Martinez, R. Jr., \& Rosenfeld, R. (2005). Firearm use, injury, and lethality in assaultive violence: An examination of ethnic differences. Homicide Studies, 9(2), 83-108. 
Osler, T., Nelson, L. S., \& Bedrick, E. J. (1999). Injury severity scoring. Journal of Intensive Care Medicine, 14(1), 9-19.

Papachristos, A. V., Braga, A. A., \& Hureau, D. M. (2012). Social networks and the risk of gunshot injury. Journal of Urban Health, 89(6), 992-1003.

Papadopoulos, I. N., Kanakaris, N. K., Danias, N., Sabanis, D., Konstantudakis, G., Christodoulou, S., Bassiakos, Y. C., \& Leukidis, C. (2013). A structured autopsybased audit of 370 firearm fatalities: Contribution to inform policy decisions and the probability of the injured arriving alive at a hospital and receiving definitive care. Accident Analysis and Prevention, 50, 667-677.

Rice, D. P., \& MacKenzie, E. J. (1989). Cost of injury in the United States: A report to Congress, 1989. Washington, D.C.: National Center for Injury Prevention and Control, Centers for Disease Control.

Sacco, V. F., \& Kennedy, L. W. (1994). The criminal event. Scarborough, ON: Nelson Canada.

Safarik, M. E., \& Jarvis, J. P. (2005). Examining attributes of homicides: Toward quantifying qualitative values of injury severity. Homicide Studies, 9(3), 183-203.

Salottolo, K., Settell, A., Uribe, P., Akin, S., Slone, D., O’Neal, E., Mains, C., \& Bar-Or, D. (2009). The impact of the AIS 2005 revision on injury severity scores and clinical outcome measures. Injury, 40(9), 999-1003.

Schaefer, J. L., \& Olsen, M. K. (1998). Multiple imputation for multivariate missing-data problems: A data analyst's perspective. Multivariate Behavioral Research, 33(4), 545-571.

Schnelby, S. M. (2002). An examination of the impact of victim, offender, and situational attributes on the deterrence effect of defensive gun use: A research note. Justice Quarterly, 19(2), 377-398.

Stevenson, M., Segui-Gomez, M., Lescohier, I., Di Scala, C., \& McDonald-Smith, G. (2001). An overview of the injury severity score and the new injury severity score. Injury Prevention, 7(1), 10-13.

Tark, J., \& Kleck, G. (2004). Resisting crime: The effect of victim action on the outcomes of crimes. Criminology, 42(4), 861-909.

Tillyer, M. S., Miller, J. M., \& Tillyer, R. (2011). The environmental and situational correlates of victim injury in non-fatal violent incidents. Criminal Justice and Behavior, 38(5), 433-452.

Tillyer, M. S., \& Tillyer, R. (2014). Violence in context: A multilevel analysis of victim injury in robbery incidents. Justice Quarterly, 31(4), 767-791. 
U. S. Department of Justice (2013). Crime in the United States, 2012. Author, Federal Bureau of Investigation. Retrieved May $30^{\text {th }}, 2014$, from http://www.fbi.gov/about-us/cjis/ucr/crime-in-the-u.s/2012/crime-in-the-u.s.2012/tables/20tabledatadecpdf.

U.S. Department of Justice (2013). National Incident-Based Reporting System (NIBRS) user manual. Washington, D.C.: Author, Federal Bureau of Investigation.

Weaver, G. S., Clifford Wittekind, J. E., Huff-Corzine, L., Corzine, J., Petee, T. A., \& Jarvis, J. P. (2004). Violent encounters: A criminal event analysis of lethal and nonlethal outcomes. Journal of Contemporary Criminal Justice, 20(4), 348-368.

Wells, W., \& Horney, J. (2002). Weapon effects and individual intent to do harm: Influences on the escalation of violence. Criminology, 40(2), 265-296.

White, I. R., Royston, P., \& Wood, A. M. (2011). Multiple imputation using chained equations: Issues and guidance for practice. Statistics in Medicine, 30(4), 377399.

Zawitz, M. W. (1996). Firearm injury from crime. Washington, DC: U.S. Department of Justice, Office of Justice Programs, Bureau of Justice Statistics.

Zimring, F. E., \& Zuehl, J. (1986). Victim injury and death in urban robbery: A Chicago study. The Journal of Legal Studies, 15(1), 1-40. 
Table 1. Distribution of Missing Cases $(N=1,417)$

\begin{tabular}{lc}
\hline Indicator & $\mathrm{N}(\%)$ \\
\hline Victim Age & $46(3 \%)$ \\
Male Victim & $16(1 \%)$ \\
Non-Black Victim & $16(1 \%)$ \\
Number of Offenders & $479(34 \%)$ \\
Number of GSW & $1(<1 \%)$ \\
Hospital Conveyance & $627(44 \%)$ \\
Distance to Hospital & $55(4 \%)$ \\
\hline
\end{tabular}


Table 2. Bivariate Summaries of Gunshot Wound Severity using Known Information

\begin{tabular}{|c|c|c|c|c|c|c|c|c|c|c|}
\hline \multirow[t]{2}{*}{ Injury Severity } & \multicolumn{2}{|c|}{ Moderate } & \multicolumn{2}{|c|}{ Serious } & \multicolumn{2}{|c|}{ Critical } & \multicolumn{2}{|c|}{ Total } & \multirow[b]{2}{*}{$\chi^{2} / F$} & \multirow[b]{2}{*}{$\mathrm{p}$} \\
\hline & $\mathrm{N} / \mathrm{M}$ & $\% / \mathrm{SD}$ & $\mathrm{N} / \mathrm{M}$ & $\% / \mathrm{SD}$ & $\mathrm{N} / \mathrm{M}$ & $\% / \mathrm{SD}$ & $\mathrm{N} / \mathrm{M}$ & $\% / \mathrm{SD}$ & & \\
\hline \multicolumn{11}{|l|}{$\begin{array}{l}\text { Individual and } \\
\text { Incident }\end{array}$} \\
\hline V Age & 28.77 & 10.35 & 28.61 & 10.11 & 31.0 & 11.78 & 28.95 & 10.43 & 3.36 & .03 \\
\hline V Gender & & & & & & & & & 2.53 & .28 \\
\hline Male & 564 & $44 \%$ & 553 & $44 \%$ & 148 & $12 \%$ & 1264 & $90 \%$ & & \\
\hline Female & 51 & $37 \%$ & 66 & $49 \%$ & 19 & $14 \%$ & 136 & $10 \%$ & & \\
\hline V Race & & & & & & & & & .39 & .82 \\
\hline Non-Black & 63 & $46 \%$ & 57 & $42 \%$ & 17 & $12 \%$ & 137 & $10 \%$ & & \\
\hline Black & 553 & $44 \%$ & 561 & $44 \%$ & 150 & $12 \%$ & 1264 & $90 \%$ & & \\
\hline N Offenders & 1.42 & .89 & 1.35 & .73 & 1.31 & .68 & 1.38 & .80 & 1.15 & .32 \\
\hline VO Relation & & & & & & & & & 40.92 & .000 \\
\hline Known & 24 & $18 \%$ & 90 & $68 \%$ & 18 & $14 \%$ & 132 & $9 \%$ & & \\
\hline Unknown & 595 & $46 \%$ & 536 & $42 \%$ & 154 & $12 \%$ & 1285 & $91 \%$ & & \\
\hline Circumstance & & & & & & & & & 68.79 & .000 \\
\hline Robbery & 211 & $47 \%$ & 202 & $45 \%$ & 38 & $8 \%$ & 451 & $32 \%$ & & \\
\hline Random & 197 & $50 \%$ & 166 & $42 \%$ & 34 & $9 \%$ & 397 & $28 \%$ & & \\
\hline Refused Info. & 84 & $37 \%$ & 81 & $36 \%$ & 61 & $27 \%$ & 226 & $16 \%$ & & \\
\hline Assault & 127 & $37 \%$ & 177 & $52 \%$ & 39 & $11 \%$ & 343 & $24 \%$ & & \\
\hline \multicolumn{11}{|l|}{ Spatiotemporal } \\
\hline Location & & & & & & & & & 67.39 & .000 \\
\hline Private & 24 & $17 \%$ & 101 & $72 \%$ & 15 & $11 \%$ & 140 & $10 \%$ & & \\
\hline Business & 62 & $44 \%$ & 60 & $43 \%$ & 19 & $13 \%$ & 141 & $10 \%$ & & \\
\hline Semi- Private & 321 & $51 \%$ & 225 & $36 \%$ & 78 & $12 \%$ & 624 & $44 \%$ & & \\
\hline Street & 212 & $41 \%$ & 240 & $47 \%$ & 60 & $12 \%$ & 512 & $36 \%$ & & \\
\hline Time of Day & & & & & & & & & 2.75 & .25 \\
\hline Night time & 399 & $45 \%$ & 393 & $44 \%$ & 99 & $11 \%$ & 891 & $63 \%$ & & \\
\hline Else & 220 & $42 \%$ & 233 & $44 \%$ & 73 & $14 \%$ & 526 & $37 \%$ & & \\
\hline Day of Week & & & & & & & & & 2.49 & .29 \\
\hline Weekend & 286 & $43 \%$ & 294 & $44 \%$ & 91 & $14 \%$ & 671 & $47 \%$ & & \\
\hline Weekday & 333 & $45 \%$ & 332 & $44 \%$ & 81 & $11 \%$ & 746 & $53 \%$ & & \\
\hline \multicolumn{11}{|l|}{ Response } \\
\hline N GSW & & & & & & & & & 17.39 & .00 \\
\hline Multiple & 105 & $36 \%$ & 132 & $45 \%$ & 54 & $19 \%$ & 291 & $21 \%$ & & \\
\hline Single & 514 & $46 \%$ & 493 & $44 \%$ & 118 & $10 \%$ & 1125 & 79\% & & \\
\hline $\mathrm{T}$ to Report (min) & 49.57 & 108.59 & 46.0 & 109.91 & 27.66 & 74.37 & 45.33 & 105.8 & 2.92 & .05 \\
\hline Hospital & & & & & & & & & 6.57 & .58 \\
\hline Prim. Trauma & 163 & $40 \%$ & 184 & $45 \%$ & 57 & $14 \%$ & 404 & $28 \%$ & & \\
\hline Else & 456 & $45 \%$ & 442 & $44 \%$ & 115 & $11 \%$ & 1013 & $72 \%$ & & \\
\hline Convey & & & & & & & & & 9.31 & .01 \\
\hline Ambulance & 305 & $61 \%$ & 122 & $24 \%$ & 77 & $15 \%$ & 504 & $64 \%$ & & \\
\hline Else & 201 & $71 \%$ & 52 & $19 \%$ & 29 & $10 \%$ & 282 & $36 \%$ & & \\
\hline Dist. to Treat (mi) & 3.57 & 2.41 & 3.38 & 1.91 & 3.22 & 1.72 & 3.44 & 2.12 & 2.25 & .11 \\
\hline
\end{tabular}


Table 3. Multinomial Logistic Regression with Imputed Estimates $(\mathrm{N}=1,417)(\mathrm{m}=50)$

\begin{tabular}{|c|c|c|c|c|c|c|}
\hline \multirow[b]{2}{*}{ Variable } & \multicolumn{2}{|c|}{ Model 1} & \multicolumn{2}{|c|}{ Model 2} & \multicolumn{2}{|c|}{ Model 3} \\
\hline & $\begin{array}{l}\text { Moderate v. } \\
\text { Critical }\end{array}$ & $\begin{array}{c}\text { Serious v. } \\
\text { Critical }\end{array}$ & $\begin{array}{l}\text { Moderate v. } \\
\text { Critical }\end{array}$ & $\begin{array}{c}\text { Serious v. } \\
\text { Critical }\end{array}$ & $\begin{array}{l}\text { Moderate v. } \\
\text { Critical }\end{array}$ & $\begin{array}{c}\text { Serious v. } \\
\text { Critical }\end{array}$ \\
\hline & OR (SE) & OR (SE) & OR (SE) & OR (SE) & OR (SE) & OR (SE) \\
\hline \multicolumn{7}{|l|}{$\begin{array}{l}\text { Individual and } \\
\text { Incident }\end{array}$} \\
\hline V Age (z) & $.84(.07)^{*}$ & $.81(.07)^{*}$ & & & $.84(.08)$ & $.81(.07)^{*}$ \\
\hline V Male & $1.26(.38)$ & $1.22(.36)$ & & & $1.20(.36)$ & $1.21(.36)$ \\
\hline V Non-Black & $.95(.29)$ & $.85(.26)$ & & & $.89(.28)$ & $.83(.26)$ \\
\hline N Offenders (z) & $1.05(.13)$ & $1.01(.12)$ & & & $1.08(.14)$ & $1.01(.12)$ \\
\hline VO Known & $.36(.13)^{* *}$ & $1.24(.38)$ & & & $.37(.13)^{*}$ & $1.26(.39)$ \\
\hline Robbery & $1.38(.37)$ & $1.26(.33)$ & & & $1.44(.39)$ & $1.29(.34)$ \\
\hline Random & $1.37(.38)$ & $1.14(.32)$ & & & 1.38 (.39) & $1.15(.32)$ \\
\hline Refused & $.33(.09)^{* * *}$ & $.32(.08)^{* * *}$ & & & $.37(.10)^{* * *}$ & $.33(.09)^{* * *}$ \\
\hline \multicolumn{7}{|l|}{ Information } \\
\hline \multicolumn{7}{|l|}{ Spatiotemporal } \\
\hline Private & $.49(.18)$ & $1.73(.56)$ & & & $.51(.19)$ & $1.79(.58)$ \\
\hline Business & $.99(.31)$ & $.87(.27)$ & & & $.96(.30)$ & $.84(.27)$ \\
\hline Semi-Private & $1.27(.25)$ & $.80(.16)$ & & & $1.32(.27)$ & $.81(.17)$ \\
\hline Night time & $1.28(.23)$ & $1.23(.22)$ & & & $1.33(.25)$ & $1.26(.23)$ \\
\hline Weekend & $.75(.13)$ & $.80(.14)$ & & & $.72(.13)$ & $.79(.14)$ \\
\hline \multicolumn{7}{|l|}{ Response } \\
\hline Multiple GSW & & & $.46(.09)^{* * *}$ & $.60(.11)^{* * * *}$ & $.47(.10)^{* * *}$ & $.60(.12)^{* *}$ \\
\hline $\mathrm{T}$ to report (z) & & & $1.32(.21)$ & $1.31(.21)$ & $1.36(.23)$ & $1.38(.23)^{*}$ \\
\hline Primary Trauma & & & $.76(.14)$ & $.86(.16)$ & $.74(.15)$ & .85 (.17) \\
\hline Convey Ambul & & & $.60(.14)^{*}$ & $.76(.18)$ & $.68(.17)$ & $.90(.23)$ \\
\hline Dist. to Treat (z) & & & $1.12(.11)$ & $1.05(.10)$ & $1.16(.12)$ & $1.06(.11)$ \\
\hline \multirow[t]{2}{*}{ Model F } & \multirow{2}{*}{\multicolumn{2}{|c|}{$\begin{array}{c}5.38 * * * \\
(26,287178.8)\end{array}$}} & \multirow{2}{*}{\multicolumn{2}{|c|}{$\begin{array}{c}3.15^{* * *} \\
(10,34023.7)\end{array}$}} & \multirow{2}{*}{\multicolumn{2}{|c|}{$\begin{array}{c}4.50 * * * \\
(36,246823.2)\end{array}$}} \\
\hline & & & & & & \\
\hline Average RVI & \multicolumn{2}{|c|}{.06} & \multicolumn{2}{|c|}{.11} & \multicolumn{2}{|c|}{.09} \\
\hline Largest FMI & \multicolumn{2}{|c|}{.49} & \multicolumn{2}{|c|}{.32} & \multicolumn{2}{|c|}{.51} \\
\hline AIC & \multicolumn{2}{|c|}{-1269.83} & \multirow{2}{*}{\multicolumn{2}{|c|}{$\begin{array}{l}-1350.88 \\
-130883\end{array}$}} & \multirow{2}{*}{\multicolumn{2}{|c|}{$\begin{array}{l}-1241.34 \\
-113095\end{array}$}} \\
\hline BIC & \multicolumn{2}{|c|}{-1185.73} & & & & \\
\hline
\end{tabular}

${ }^{*} \mathrm{p}<.05,{ }^{* *} \mathrm{p}<.01,{ }^{* * *} \mathrm{p}<.001 ;$ OR $=$ Odds Ratio 
it is important to keep in mind that single incidents may have a number of non-fatal victims as well as one or more victims with fatal injuries (e.g., dead on scene and/or dead on arrival to treatment center). Fatalities are not included in these data. 